\title{
Laying out the Evidence for the Persistence of Neurogenesis in the
} \section{Adult Human Hippocampus}

Golo Kronenberg ${ }^{1}$, Friederike Klempin²,3

1. College of Life Sciences, University of Leicester and Leicestershire Partnership National Health Service Trust, Leicester, UK. Electronic address: gdk7@leicester.ac.uk

2. Charité-Universitätsmedizin Berlin, corporate member of Freie Universität Berlin, Humboldt-Universität zu Berlin, and Berlin Institute of Health, Klinik und Poliklinik für Psychiatrie und Psychotherapie, 10117 Berlin, Germany

3. Max Delbrück Center for Molecular Medicine (MDC), 13125 Berlin, Germany. Electronic address: friederike.klempin@mdc-berlin.de

Comment on

Neurobiological effects of aerobic exercise, with a focus on patients with schizophrenia 
Dear Editor,

We read with great interest the recent review article by Isabel Maurus and colleagues [1], which succinctly summarizes the main beneficial effects of aerobic exercise on negative and cognitive symptoms in schizophrenia and the key neurobiological mechanisms that may underpin these effects. The authors rightly highlight, among other mechanisms, the upregulation of brain-derived neurotrophic factor (BDNF) together with structural changes associated with aerobic exercise. Neurogenesis is a key aspect of structural plasticity and a wealth of experimental knowledge has accumulated on the robust neurogenesis-inducing effects of physical activity in rodents. Moreover, decreased cell proliferation in the dentate gyrus was found in schizophrenia, thereby providing strong, but not conclusive, evidence that reduced neurogenesis forms part of the underlying disease process in the brain [2]. We therefore think that, in their review, the authors may have been overly cautious in their discussion of the generation of new neurons in the adult hippocampus. This is likely due to a recent report that has cast doubt on the persistence of neurogenesis in the adult human dentate gyrus [3]. Considering the wide readership of The European Archives of Psychiatry and Clinical Neuroscience among students, clinical academics, and researchers, this letter is intended to provide, in brief form, some perspective on this important debate.

At the beginning of the 20th century, Ramon y Cajal famously proclaimed that "nerve paths are something fixed and immutable: everything may die, nothing may be regenerated." Ever since then, the concept of neurogenesis has met with both healthy skepticism, and occasionally, entrenched resistance. In the end, this has resulted in 
important new technical and scientific insights such as showing that DNA synthesis and incorporation of thymidine analogue $\mathrm{BrdU}$ is not confined to de novo neurogenesis, but may also occur in damaged and dying neurons [e.g., 4]. Similarly, it quickly became apparent that cell proliferation as such is not a reliable indicator of neurogenesis because the survival of newly generated cells can be independent of increased cell proliferation $[5,6]$. Furthermore, even in the subgranular zone, cell proliferation is not restricted to neural stem and progenitor cells. In response, the field has undertaken enormous efforts to characterize developmental stages of neurogenesis through time-course studies using $\mathrm{BrdU}$ together with sequential immunohistochemistry of markers of neuronal maturation [e.g., 7, 8]. Alongside this, new techniques such as retroviral labeling and whole-cell recordings have been brought to bear to demonstrate that new neurons become functionally integrated into hippocampal circuitry [9]. The persistence of neurogenesis in the human dentate gyrus into old age has been described by multiple groups, and it is probably fair to say that, to a certain extent, the study by Sorrells and colleagues represents an outlier [3]. Generally speaking, immunohistochemistry of postmortem human brain is notoriously challenging, and even small deviations from an established protocol may have huge effects. Therefore, technical issues such as, inter alia, duration of fixation, fixative, and use of anatomical references together with the use of unbiased stereology deserve exquisite attention. Recent painstaking reports published in response to Sorrells and co-workers $[10,11]$ combined human brain samples obtained under highly standardized conditions with state-of-the-art tissue processing together with meaningful control experiments [11]. The new study by Moreno-Jiménez and colleagues provides convincing evidence for high numbers of immature neurons in the dentate gyrus in healthy aging [11]. Importantly, the authors highlight crucial 
methodological differences that may explain, at least in part, the discrepancy of their results with the results reported by Sorrells et al. $[3,11]$. Furthermore, additional approaches beyond mere histology such as BrdU birth dating [12] and incorporation of nuclear bomb test derived $14 \mathrm{C}$ [13] add to a confluence of evidence for neurogenesis occurring in the adult human hippocampus. Finally, high yields of progenitor cells can be cultured from adult human postmortem hippocampus [14].

In the aggregate, we believe that the preponderance of the evidence clearly indicates that neurogenesis persists in the adult human dentate gyrus. It will be interesting to see how the field will overcome the considerable technical, ethical, and scientific challenges to elucidating further the role of neurogenesis in the adult human dentate gyrus and how it relates to neuropsychiatric disorders.

Conflict of Interest Statement

On behalf of all authors, the corresponding author states that there is no conflict of interest. 


\section{References}

[1] Maurus I, Hasan A, Röh A, Takahashi S, Rauchmann B, Keeser D, Malchow B, Schmitt A, Falkai P (2019) Neurobiological effects of aerobic exercise, with a focus on patients with schizophrenia. Eur Arch Psychiatry Clin Neurosci 269(5):499-515 [2] Reif A, Fritzen S, Finger M, Strobel A, Lauer M, Schmitt A, Lesch KP (2006) Neural stem cell proliferation is decreased in schizophrenia, but not in depression. Mol Psychiatry 11(5):514-22

[3] Sorrells SF, Paredes MF, Cebrian-Silla A, Sandoval K, Qi D, Kelley KW, James D, Mayer S, Chang J, Auguste KI, Chang EF, Gutierrez AJ, Kriegstein AR, Mathern GW, Oldham MC, Huang EJ, Garcia-Verdugo JM, Yang Z, Alvarez-Buylla A (2018) Human hippocampal neurogenesis drops sharply in children to undetectable levels in adults. Nature 555(7696):377-381

[4] Burns KA, Ayoub AE, Breunig JJ, Adhami F, Weng WL, Colbert MC, Rakic P, Kuan CY (2007) Nestin-CreER mice reveal DNA synthesis by nonapoptotic neurons following cerebral ischemia hypoxia. Cereb Cortex 17(11):2585-92

[5] Kronenberg G, Reuter K, Steiner B, Brandt MD, Jessberger S, Yamaguchi M, Kempermann G (2003) Subpopulations of proliferating cells of the adult hippocampus respond differently to physiologic neurogenic stimuli. J Comp Neurol 467(4):455-63

[6] Leuner B, Waddell J, Gould E, Shors TJ (2006) Temporal discontiguity is neither necessary nor sufficient for learning-induced effects on adult neurogenesis. J Neurosci 26(52):13437-42

[7] Kempermann G, Jessberger S, Steiner B, Kronenberg G (2004) Milestones of neuronal development in the adult hippocampus. Trends Neurosci 27(8):447-52 
[8] Steiner B, Klempin F, Wang L, Kott M, Kettenmann H, Kempermann G (2006) Type-

2 cells as link between glial and neuronal lineage in adult hippocampal neurogenesis. Glia 54:805-814.2006.

[9] van Praag H, Schinder AF, Christie BR, Toni N, Palmer TD, Gage FH (2002) Functional neurogenesis in the adult hippocampus. Nature 415(6875):1030-4 [10] Boldrini M, Fulmore CA, Tartt AN, Simeon LR, Pavlova I, Poposka V, Rosoklija GB, Stankov A, Arango V, Dwork AJ, Hen R, Mann JJ (2018) Human Hippocampal Neurogenesis Persists throughout Aging. Cell Stem Cell 22(4):589-599

[11] Moreno-Jiménez EP, Flor-García M, Terreros-Roncal J, Rábano A, Cafini F, Pallas-Bazarra N, Ávila J, Llorens-Martín M (2019) Adult hippocampal neurogenesis is abundant in neurologically healthy subjects and drops sharply in patients with Alzheimer's disease. Nat Med 25(4):554-560

[12] Eriksson PS, Perfilieva E, Björk-Eriksson T, Alborn AM, Nordborg C, Peterson DA, Gage FH (1998) Neurogenesis in the adult human hippocampus. Nat Med $4(11): 1313-7$

[13] Spalding KL, Bergmann O, Alkass K, Bernard S, Salehpour M, Huttner HB, Boström E, Westerlund I, Vial C, Buchholz BA, Possnert G, Mash DC, Druid H, Frisén $J(2013)$ Dynamics of hippocampal neurogenesis in adult humans. Cell 153(6):12191227

[14] Palmer TD, Schwartz PH, Taupin P, Kaspar B, Stein SA, Gage FH (2001) Cell culture. Progenitor cells from human brain after death. Nature. 411(6833):42-3 